\title{
A note on the sunspot and prominence records made by Angelo Secchi during the period 1871-1875
}

\author{
Víctor M. S. Carrasco ${ }^{1,2, *} \odot$, José M. Nogales ${ }^{3} \odot$, José M. Vaquero ${ }^{2,4} \oplus$, Theodosios Chatzistergos ${ }^{5,6} \odot$, \\ and Ilaria Ermolli ${ }^{5}$ \\ ${ }^{1}$ Departamento de Física, Universidad de Extremadura, 06071 Badajoz, Spain \\ ${ }^{2}$ Instituto Universitario de Investigación del Agua, Cambio Climático y Sostenibilidad (IACYS), Universidad de Extremadura, \\ 06006 Badajoz, Spain \\ ${ }^{3}$ Departamento de Expresión Gráfica, Universidad de Extremadura, 06800 Mérida, Spain \\ ${ }^{4}$ Departamento de Física, Universidad de Extremadura, 06800 Mérida, Spain \\ ${ }^{5}$ INAF Osservatorio Astronomico di Roma, Via Frascati 33, 00078 Monte Porzio Catone, Italy \\ ${ }^{6}$ Max Planck Institute for Solar System Research, Justus-von-Liebig-weg 3, 37077 Göttingen, Germany
}

Received 5 August 2021 / Accepted 1 September 2021

\begin{abstract}
Angelo Secchi (1818-1878) was an Italian Jesuit who made relevant scientific contributions in geophysics, meteorology, and astrophysics. He was a well-known pioneer in solar physics due to his theories and observations. Secchi published Le Soleil (The Sun) a summary of knowledge about our star in that time. Moreover, he published in this book his sunspot and prominence observations made during the period 1871-1875. In this work, we present a machine-readable version of these observations and a preliminary analysis of them.
\end{abstract}

Keywords: sunspots / prominences / solar activity / historical records / Angelo Secchi

\section{Introduction}

Pietro Angelo Secchi (1818-1878) was an Italian Jesuit who made relevant scientific contributions (Moigno, 1879; Chinnici, 2019; Chinnici \& Consolmagno, 2021). He entered the Jesuit order at Rome in 1833. He studied in the Collegio Romano and later was a professor of Physics and Mathematics. Between 1848 and 1850, Secchi lived in England and worked at Stonyhurst College with Father Weld, the first director of the observatory of that institution. Later, he moved to the United States, where he got his doctorate in theology and taught natural sciences at Georgetown University. He returned to Rome in 1850 and became the director of the Osservatorio del Collegio Romano.

Secchi carried out studies in different scientific areas, for example, meteorology and astronomy (Chinnici \& Consolmagno, 2021; Udías, 2021). Secchi was interested, for instance, in climate and the relationship between magnetic observations and weather. Moreover, he constructed the meteorograph, an instrument to record automatically atmospheric pressure, temperature, wind, and rain in short intervals (Anonymous, 1879). As an astronomer, Secchi was the first to make systematic

\footnotetext{
*Corresponding author: vmscarrasco@unex.es
}

spectroscopic observations in stellar classification. Thus, one of his main astronomical works was the spectral classification of stars in four different types. Besides, Secchi was the first who suggested that the solar core is gaseous, and its temperature decreases from the center to the surface. He was a pioneer in applying the heliospectrograph. He also did significant works in solar observations (including eclipses), comets (discovering the comet currently known as C/1853 E1 Secchi), planets, inter alia. In particular, he was an outstanding astronomer in studying sunspots and prominences, observing them both visually and spectroscopically. Secchi provided the first demonstration that prominences are solar phenomena. Some of his theories on sunspots, granulation, and prominences are outdated, but he had a great relevance on astronomy and solar physics of that time.

Many societies around the world recognized the excellent work made by Secchi, such as the Royal Astronomical Society and the French Academy, he was even the president of the Academia dei Nuovi Lincei. Undoubtedly, Secchi is one of the most relevant solar physicists of history. He kept a detailed archive of drawings of the Sun since 1858 in his notebooks. The drawings depict sunspots, distinguishing between umbra and penumbra, along with facular regions near the limb and prominences. Analysis of the archival documents reveals that in the 1870s, Secchi's collaborators made observations, among others Giuseppe Lais, Gaspare Ferrari and Francesco Marchetti. 
Tавцвav A. - Résultats des obsenations des protubérances et des taches solaires, du 23 avril 1871 au 11 décembre 1875.

\begin{tabular}{|c|c|c|c|c|c|c|c|c|c|}
\hline \multirow{3}{*}{$\begin{array}{c}\text { ROTATIOSS. } \\
\text {, }\end{array}$} & \multirow{3}{*}{$\begin{array}{c}\text { COMMENCEMEst } \\
\text { des } \\
\text { Moratioss. } \\
2\end{array}$} & \multicolumn{4}{|c|}{ PROTUBÉRANCES. } & \multicolumn{4}{|c|}{ TACHES. } \\
\hline & & \multicolumn{2}{|c|}{$\begin{array}{l}\text { xOMnk: тотAL } \\
\text { des protubérances dans } \\
\text { I'hémisphere }\end{array}$} & \multirow{2}{*}{$\begin{array}{c}\begin{array}{c}\text { vomane } \\
\text { des } \\
\text { jours } \\
\text { drobservation. }\end{array} \\
5\end{array}$} & \multirow{2}{*}{$\begin{array}{c}\text { sombne total } \\
\text { divisé } \\
\text { par } \\
\text { lo nombre } \\
\text { de jours. } \\
6\end{array}$} & \multirow{2}{*}{$\begin{array}{c}\text { NOMBRE } \\
\text { de } \\
\text { groupas. } \\
7\end{array}$} & \multirow{2}{*}{$\begin{array}{c}\text { SePEnvicie } \\
\text { des } \\
\text { taches. } \\
8\end{array}$} & \multirow{2}{*}{$\begin{array}{c}\text { Jovns } \\
\text { d'observation } \\
\text { des } \\
\text { taches. } \\
9 \\
\end{array}$} & \multirow{2}{*}{$\begin{array}{c}\text { SUPERFicie } \\
\text { divisee } \\
\text { par } \\
\text { lo nombre } \\
\text { de jours. } \\
10 \\
\end{array}$} \\
\hline & & 3 & 4 & & & & & & \\
\hline $1 \ldots \ldots \ldots$ & 23 avril $1871 \ldots \ldots$ & 156 & 200 & $2 j$ & $1 \mathfrak{q}, 2 i$ & 27 & 4237 & 26 & 162,9 \\
\hline II $\ldots \ldots \ldots \ldots$ & 22 mai........... & 188 & 196 & 24 & 16,12 & 39 & 2080 & 36 & 80,0 \\
\hline III.......... & 19 juin. ......... & 187 & 199 & 26 & $14,8 j$ & 23 & 1737 & 26 & 66,4 \\
\hline IV......... & 16 juillet. . . . . . . & 232 & 220 & 28 & 15,78 & 19 & 2346 & 28 & 90,9 \\
\hline $\mathbf{v} \ldots \ldots \ldots$ & 13 aoùt. . . . . . . . & 174 & 200 & 25 & 14,96 & 23 & $30:\}_{2}$ & 25 & 121,6 \\
\hline vi........ & 10 septembre....... & 133 & 140 & 18 & 19,61 & 20 & 1363 & 27 & 56,7 \\
\hline vil......... & 8 octobre........ & $9^{2}$ & 108 & 14 & 1,28 & 23 & 1342 & 18 & 74,5 \\
\hline vill $\ldots \ldots \ldots$ & 5 novembre....... & 50 & 60 & 8 & $13,7^{5}$ & 30 & 1021 & 17 & 60,0 \\
\hline $\mathbf{I x} \ldots \ldots \ldots$ & 3 décembre. ...... & 116 & 133 & 16 & 15,56 & 17 & 1079 & 18 & 63,4 \\
\hline $\mathbf{x} \ldots \ldots \ldots$ & I janvier $187, \ldots$ & 80 & 116 & 14 & 14,00 & 25 & 980 & 19 & 51,6 \\
\hline $\mathbf{x I} . \ldots \ldots \ldots$ & 27 janvier........... & 109 & 123 & 17 & 13,65 & 27 & 2121 & 23 & $9^{2,2}$ \\
\hline xul......... & 25 fevrrier......... & 107 & 109 & 14 & $15,4^{3}$ & 20 & 1338 & 19 & 70,5 \\
\hline xIII........ & 24 mars............. & 76 & $8 i$ & 13 & 12,07 & 28 & 1699 & 20 & 84,9 \\
\hline xIv. ...... & 23 avril........... & 110 & 109 & 18 & 12,16 & 20 & 2358 & 24 & 98,2 \\
\hline $\mathbf{x} \mathbf{v} \ldots \ldots \ldots$ & 21 mai........... & 115 & 114 & 20 & 11,95 & 21 & 2762 & 27 & 102,3 \\
\hline xvi....... & 18 juin. ........... & 145 & 146 & 36 & 11,19 & $3 \mathbf{I}$ & $26 / 8$ & 27 & $9^{8,0}$ \\
\hline xvil......... & 16 juillet. . . . . . . . & $\mathbf{1 6 1}$ & 194 & 28 & 12,68 & 26 & 2095 & 28 & $7 f, 8$ \\
\hline Xvill. ...... & 13 aoùt.......... & ' '́o & 147 & 25 & 1,48 . & 28 & 877 & 26 & 33,7 \\
\hline $\mathbf{x I X} \ldots \ldots \ldots$ & 9 septembre $\ldots \ldots$ & 68 & 88 & 15 & 10,40 & 19 & 1576 & 22 & 71,6 \\
\hline $\mathbf{x x} \ldots \ldots \ldots$ & 5 octobre. .......... & 65 & 64 & 19 & 9,21 & 18 & 1205 & 19 & 63,1 \\
\hline $\mathbf{x} \mathbf{x} \mathbf{1} \ldots \ldots \ldots$ & 5 novembre....... & 62 & 68 & 11 & 11,82 & 23 & 2803 & 21 & 133,5 \\
\hline xxil........ & q décembre. ...... & 48 & 62 & 9 & 13,32 & 17 & 1206 & 19 & 63,5 \\
\hline xxill....... & I janvier is 3 3...... & 76 & 㭌 & $1 j$ & 10,00 & 23 & 1332 & 20 & 66,6 \\
\hline xxiv....... & 29 janvier........... & 84 & 116 & 19 & 10,53 & 23 & 2659 & 23 & 115,6 \\
\hline $\mathbf{x} \mathbf{x} \mathbf{v} \ldots \ldots$ & 26 février........... & 53 & 77 & 15 & 8,66 & 19 & 2258 & 20 & 112,9 \\
\hline $\mathbf{x x v I} \ldots \ldots$ & 26 mars......... & 91 & 97 & 18 & 10,44 & 17 & 1338 & 21 & 63,7 \\
\hline xx viı...... & 23 avril. ........ & 87 & 93 & 17 & 10,59 & 11 & 539 & 31 & 25,6 \\
\hline
\end{tabular}

Fig. 1. Table A published by Secchi, including the sunspot and prominence observations during 1871-1875 [source: Secchi, 1875, p. 160].

There are several published tables of measurements of solar features by Secchi in archival documents (Secchi, 1855, 1864, 1871a, 1871b, 1872). One such summary of his knowledge and observations of the Sun was his book titled "The Sun". It was first published in 1870 in French as Le Soleil, followed by German, Spanish, and Italian translations in 1872, 1879, and 1884. However, it was not until the second French edition (published in 1875) that tables summarizing information on solar features were included. The focus of this work is to present Secchi's solar observations published in Le Soleil (Secchi, 1875).

The outline of this work is as follows. Once contextualized the work of Secchi, highlighting his scientific figure, we present the sunspot and prominence observations published by Secchi (1875) in Section 2. A primary analysis of these observations is shown in Section 3. A summary and the main conclusion of this work are exposed in Section 4.

\section{Solar Activity Records by Secchi in Le Soleil}

A summary of Secchi's sunspot and prominence observations for 1871-1875 was published in the second French edition of Le Soleil (Secchi, 1875). The first volume of this edition is divided into four parts. The first one is about the structure of the Sun, the second one on its surface, the third one on the solar atmosphere, and the last one on the eclipses. The second volume is also divided into four parts. In this case, each part deals with (1) sunspots, solar prominences and eruptions, (2) temperature of the Sun, (3) solar activity, and (4) stars.

Secchi included his sunspot and prominence records in the first part of the second volume of Le Soleil. These observations are presented in seven tables. The information included in the tables are:

- Table A - number of observation days, prominences, and sunspot groups, in addition to group areas.

- Table B - number of prominences by heliographic latitudes.

- Table C - average height of the prominences by heliographic latitudes.

- Table D - number of prominences larger than $64^{\prime \prime}$ by heliographic latitudes.

- Table E - average width of the prominences by heliographic latitudes.

- Table F - average area of the prominences by heliographic latitudes. 


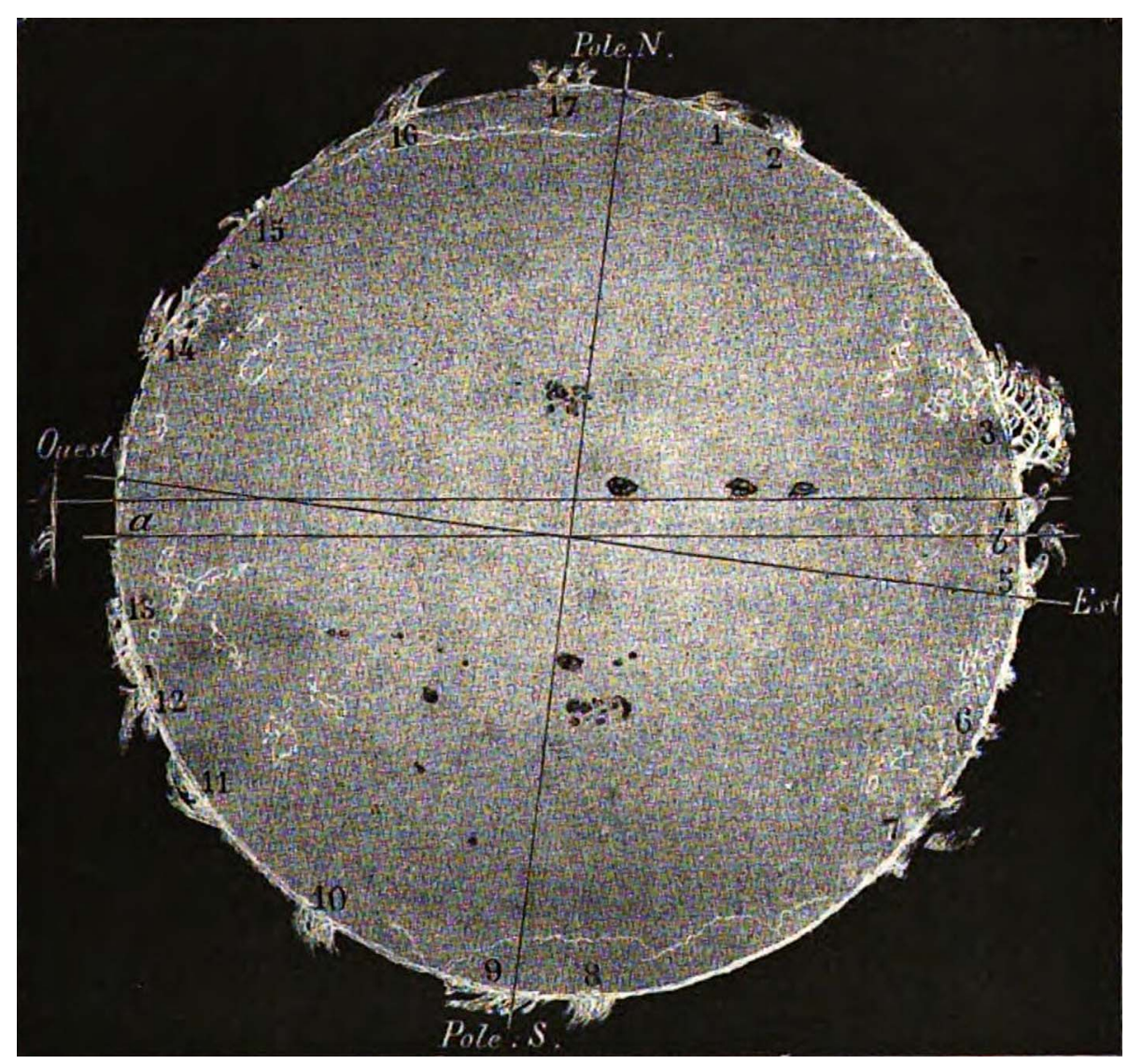

Fig. 2. Illustration of the solar observations made by Secchi on 23 July 1871 between 8:30 and 9:55 am. Prominences (white regions from solar limb numbered from 1 to 17), sunspots (black regions on the solar disc), and faculae (white regions on the solar disc) were recorded. Inclined black lines indicate the solar axes ("Est" means East, "Ouest" is West, "Pole N." and "Pole S." indicate the solar north and south, respectively). The horizontal black lines are upper line - a reference indicated by Secchi to obtain the position of the celestial equator, and lower line - its parallel diameter given by "a-b" line representing the celestial equator [source: Secchi, 1875, p. 131].

Table 1. Some example lines of the machine-readable version presented in this work on the sunspot and prominence observations made by Secchi published in Le Soleil. The first column shows the number of each solar rotation in Roman numerals, followed by the date (year-monthday format) when the solar rotation starts, the number of prominences in the northern and southern hemisphere respectively, the number of observation days of prominences, the daily average of the prominence number, the number of new sunspot groups observed for each solar rotation, the sunspot area (one unit is defined such as $1 \mathrm{~mm}$ in height corresponds to 8 arcseconds and one degree at the limb corresponds to 16 arcseconds), the number of observation days in the case of sunspots, and the daily average of sunspot area.

\begin{tabular}{|c|c|c|c|c|c|c|c|c|c|}
\hline $\begin{array}{l}\text { Solar } \\
\text { rotation }\end{array}$ & $\begin{array}{l}\text { Start } \\
\text { date }\end{array}$ & $\begin{array}{l}\text { Prom. number } \\
\text { (north) }\end{array}$ & $\begin{array}{l}\text { Prom. number } \\
\quad \text { (south) }\end{array}$ & $\begin{array}{l}\text { Prom. obs. } \\
\text { days }\end{array}$ & $\begin{array}{l}\text { Prom. } \\
\text { average }\end{array}$ & $\begin{array}{l}\text { Group } \\
\text { number }\end{array}$ & $\begin{array}{c}\text { Sunspot } \\
\text { area }\end{array}$ & $\begin{array}{l}\text { Obs. } \\
\text { days }\end{array}$ & $\begin{array}{c}\text { Area } \\
\text { average }\end{array}$ \\
\hline I & $1871-04-23$ & 156 & 200 & 25 & 14.24 & 27 & 4237 & 26 & 162.9 \\
\hline LVI & $1875-12-11$ & 37 & 30 & 13 & 5.2 & 8 & 104 & 15 & 6.9 \\
\hline
\end{tabular}

- Table G - faculae extent as a function of circumference degrees by heliographic latitudes.

Each row in the tables shows the statistics calculated by Secchi of the variables previously indicated for each solar rotation. Each table includes 62 solar rotations ( 62 rows), named by Roman numerals from I to LXII and defined with dates different from the known Carrington rotation. The first one starts on 23 April 1871 and the last one on 11 December 1875. Figure 1 shows an example page of these tables. Note that each solar rotation does not include the same number of days.

Secchi explained that there are two methods to observe prominences. One is to record them in an image composed by lines divided by 360 parts (representing the degrees of a circumference). The advantage here is that observations in different days can be put together in the same sheet, which allows us to see the daily evolution of the prominences. However, Secchi $(1875$, p. 129) points out that the relationships between 
Tableav B. - Nombre des protubérances distribuées par latitudes heiliographiques.

\begin{tabular}{|c|c|c|c|c|c|c|c|c|c|c|c|c|c|c|c|c|c|c|c|c|c|c|}
\hline \multirow{2}{*}{ gotatioxs. } & \multicolumn{9}{|c|}{ UEMISPHËER KORD. } & \multicolumn{9}{|c|}{ HĖMISPUERE SUD. } & \multicolumn{2}{|c|}{$\begin{array}{c}\text { Nombne } \\
\text { total. }\end{array}$} & \multirow{2}{*}{$\left|\begin{array}{c}\text { Nomane } \\
\text { total } \\
\text { dirisé } \\
\text { por le } \\
\text { nombre } \\
\text { de Jours. }\end{array}\right|$} & \multirow{2}{*}{ 递 } \\
\hline & $\begin{array}{l}90^{\circ} \\
\text { a } 80^{\circ}\end{array}$ & $\begin{array}{l}80 \\
70\end{array}$ & $\begin{array}{l}70 \\
10\end{array}$ & $\begin{array}{l}60 \\
50\end{array}$ & $\begin{array}{l}50 \\
40\end{array}$ & $\begin{array}{l}60 \\
30\end{array}$ & $\begin{array}{l}30 \\
\text { 90 }\end{array}$ & $\begin{array}{l}20 \\
10\end{array}$ & 10 & $\begin{array}{l}00 \\
100\end{array}$ & $\begin{array}{l}10 \\
20\end{array}$ & $\begin{array}{l}20 \\
30\end{array}$ & $\begin{array}{l}30 \\
40\end{array}$ & $\begin{array}{l}40 \\
80\end{array}$ & $\begin{array}{l}50 \\
60\end{array}$ & $\begin{array}{l}60 \\
70\end{array}$ & $\begin{array}{l}70 \\
80\end{array}$ & $\begin{array}{l}80 \\
90\end{array}$ & N. & s. & & \\
\hline I... & to & 12 & 11 & 23 & 13 & 20 & 30 & 21 & 17 & 36 & 36 & 27 & 23 & 22 & 7 & 17 & 20 & 12 & 156 & 200 & 14,24 & 25 \\
\hline II.... & 6 & 32 & 18 & $\because$ & 14 & 28 & 27 & 26 & 36 & 28 & 35 & 30 & 21 & 25 & 9 & 24 & 18 & 9 & 188 & 199 & 16,12 & 24 \\
\hline III. . & 16 & 23 & 13 & 8 & 21 & 26 & 27 & 24 & 29 & 24 & 30 & 26 & 26 & 19 & 12 & 15 & 35 & 13 & 187 & 199 & $14,8 j$ & 26 \\
\hline IV... & 26 & 24 & 10 & 14 & 21 & 28 & 34 & 35 & 3o & 36 & 33 & 34 & 35 & 25 & 5 & 10 & 26 & 26 & 232 & 220 & 15,78 & 28 \\
\hline v.... & 19 & 20 & 2 & 14 & 15 & 25 & 29 & 27 & 23 & 25 & 24 & 33 & 28 & 22 & 6 & 7 & 31 & 24 & 47 & 200 & 14,96 & 25 \\
\hline vi... & 13 & 10 & 3 & 5 & 15 & 19 & 18 & 20 & 21 & 17 & 21 & 23 & 19 & 13 & 5 & 6 & 22 & 14 & 123 & 140 & 14,61 & 18 \\
\hline vit.. & 14 & 8 & 5 & 2 & II & 15 & 12 & 15 & 10 & 14 & 17 & 21 & 11 & 10 & 6 & 3 & 11 & 15 & $9^{3}$ & 108 & 14,28 & 14 \\
\hline vilI. & 4 & 5 & 3 & 3 & $\cdot 4$ & 6 & 8 & 10 & 7 & 9 & 10 & 9 & 4 & 7 & 3 & 2 & f & 12 & 50 & 60 & $13,7^{5}$ & 8 \\
\hline IX... & 11 & 8 & 8 & 8 & iI & 15 & 18 & 17 & 20 & 23 & 23 & 20 & 16 & 13 & 8 & 3 & 13 & 15 & 116 & 133 & 15,56 & 16 \\
\hline $\mathbf{x} \ldots$ & 3 & 7 & 9 & 4 & 9 & 12 & 14 & 15 & 13 & 15 & 19 & 23 & 18 & 13 & 11 & 3 & 8 & 6 & 80 & 116 & 14,00 & 14 \\
\hline XI.. & 13 & 8 & 5 & 4 & 12 & 11 & 21 & 18 & 17 & 22 & $1 / 4$ & 24. & 20 & 11 & 9 & 8 & 4 & 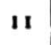 & 109 & 123 & 13,65 & 17 \\
\hline XII... & 6 & 7 & 8 & 10 & 14 & 17 & 17 & 17 & 9 & 19 & 23 & 15 & 17 & 9 & 11 & 5 & 4 & 7 & 107 & 109 & 15,43 & 14 \\
\hline xIII ......... & I & 4 & 4 & 7 & 7 & 15 & 14 & iI & 13 & 12 & 16 & 17 & 14 & 5 & 8 & 2 & 4 & 3 & 76 & 81 & 12,07 & 13 \\
\hline xiv ...... & 4 & 2 & 8 & 8 & 18 & 20 & 20 & 17 & 13 & 14 & 23 & 23 & 18 & 9 & 10 & 5 & 3 & 4 & 110 & 109 & 12,16 & 18 \\
\hline $\mathbf{x v} \ldots \ldots \ldots$ & 1 & 1 & 2 & 15 & 18 & 19 & 18 & 19 & 22 & 21 & 17 & 27 & 24 & 14 & 6 & 1 & 4 & $"$ & 115 & 114 & 11,45 & 20 \\
\hline xvi....... & 3 & $\mathbf{I}$ & 3 & 14 & 17 & 28 & 17 & 29 & 23 & 22 & 28 & 35 & 24 & 20 & 11 & 3 & $i$ & 2 & 145 & 146 & 11,19 & 26 \\
\hline xvil........ & $n$ & 1 & 2 & 6 & 30 & 37 & 30 & 32 & 23 & 27 & 30 & 29 & 28 & 33 & 14 & 3 & $n$ & " & $16 t$ & 194 & 12,68 & 28 \\
\hline xvill....... & 2 & 2 & 4 & 16 & 10 & 26 & 3o & 27 & 23 & 23 & 30 & 23 & 27 & 26 & 13 & $"$ & 2 & 3 & 140 & 147 & 11,48 & 25 \\
\hline xix ........ & $n$ & 1 & "I & 6 & 7 & 15 & 15 & 13 & 12 & 11 & 14 & 11 & 13 & 14 & 9 & 2 & $"$ & 1 & 68 & 88 & 10,40 & 15 \\
\hline $\mathbf{x x} \ldots . . . \ldots$ & $"$ & 2 & $"$ & 5 & 11 & 8 & 12 & 12 & 15 & 10 & 12 & 17 & 11 & 9 & 3 & 1 & $n$ & 1 & 65 & 64 & 9,21 & 14 \\
\hline xxI........ & 2 & 3 & $\mathbf{I}$ & 7 & 5 & 10 & 11 & 8 & 15 & 10 & 12 & 15 & 11 & 11 & 7 & $\mathbf{I}$ & 1 & $n$ & 62 & 68 & 11,82 & II \\
\hline xxII ....... & $"$ & $"$ & 1 & $i$ & 6 & 10 & 10 & 8 & 9 & 10 & 9 & 11 & 9 & 10 & 8 & 2 & 3 & $n$ & 18 & 62 & 12,22 & 9 \\
\hline xxill....... & $n$ & 2 & 3 & 8 & 10 & 14 & 14 & 13 & 12 & 13 & 15 & 13 & 9 & 9 & 10 & 3 & 1 & I & 76 & 74 & 10,00 & 15 \\
\hline xxiv....... & 2 & 2 & 4 & 9 & 9 & 13 & 23 & 12 & 10 & 23 & 28 & 19 & 12 & 16 & 15 & 3 & $"$ & " & 84 & 116 & 10,53 & 19 \\
\hline $\mathbf{x x v} \ldots . .$. & $"$ & $"$ & 2 & 7 & 10 & 7 & 10 & 6 & 11 & 15 & 18 & 10 & 13 & 9 & 8 & 2 & $" \prime$ & 2 & 53 & 77 & 8,66 & 15 \\
\hline xxv1....... & $n$ & 2 & 2 & 13 & 11 & 18 & 17 & 12 & 16 & 15 & 18 & 20 & 21 & 7 & 9 & 5 & $"$ & 2 & 91 & 97 & 10,94 & 18 \\
\hline XXvil.... & " & " & 9 & 7 & 10 & 20 & 17 & 9 & 15 & 13 & 18 & 24 & 13 & 12 & 8 & 4 & $"$ & $\mathbf{I}$ & 87 & 93 & 10,59 & 17 \\
\hline XXXIII .... & $"$ & " & $n$ & 8 & 7 & 15 & 9 & 10 & 18 & 13 & 18 & 11 & $\|$ & 81 & 7 & 3 & 1 & $"$ & 67 & 72 & 8,18 & 17 \\
\hline
\end{tabular}

Fig. 3. Table B published by Secchi, including information on the distribution of prominences in heliographic latitudes [source: Secchi, 1875, p. 162].

prominences and other solar phenomena such as sunspots cannot be seen by that method. For that reason, Secchi decided to use another method. He recorded all solar phenomena in the same observation sheet by representing them in a disc with a disc projection of $244 \mathrm{~mm}$ diameter. Secchi (1875, p. 130) also noted that $1 \mathrm{~mm}$ in height in his drawings corresponds to 8 arcseconds and one degree in the drawing at the limb corresponds to 16 arcseconds. Figure 2 shows the reproduction of the drawing made by Secchi around the maximum of Solar Cycle 11, on 23 July 1871 between 8:30 and 9:55 am.

We have made a machine-readable version of the data included in the seven tables previously mentioned. Our digitized version can be downloaded on the Historical Archive of Sunspot observations (http://haso.unex.es). Table 1 depicts some example lines of the machine-readable version presented in this work.

\section{A primary analysis of the observations}

We have consulted the second French edition of Le Soleil as well as the Spanish translation. On the one hand, we also detected errors in the values published in both editions, such as, for example, in Table A for rotation VI where the daily average of sunspot areas is 56.7 (see Fig. 1), but if we divide the total area for that rotation by the number of observation days, it is 46.7. Then, this error seems due to an erratum as well as others like that. On the other hand, we found some differences in the values included in the tables of both editions. For example, in Table B for rotation II, the total number of prominences observed in the northern hemisphere was 188 according to the second French edition of Le Soleil (Fig. 3), and it is 198 according to the Spanish translation. In this case, if we sum the total number of prominences recorded in different heliographic coordinates, the result is 188. Therefore, that also seems erratum in the Spanish edition. Note that we also provide a list of suspicious data in our machine-readable version of the data.

The number of groups in each rotation recorded by Secchi in Table A and the number of observation days, is represented in Figure 4 (top panel). It can be seen that how, in general, the number of groups decreases from the first records by Secchi to the last ones. That is because the maximum of that solar cycle (Solar Cycle 11) was around those first observations. The following minimum was in 1878 according to the sunspot number index provided by the Sunspot Index and Long-term Solar Observations (SILSO, https://wwwbis.sidc.be/silso). We have also depicted the groups recorded in the Royal Greenwich 


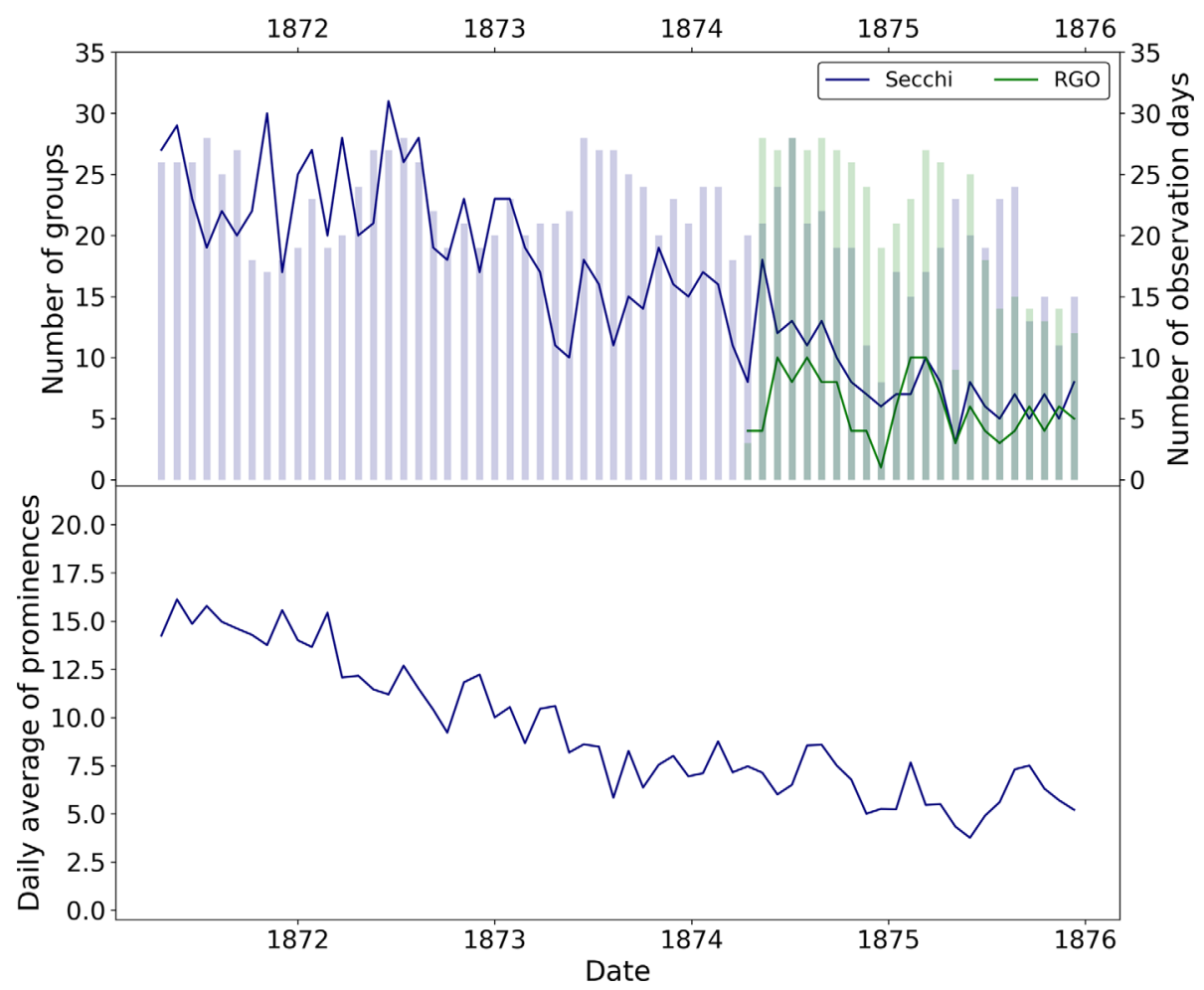

Fig. 4. Top panel: number of groups in each rotation (blue line) recorded by Secchi for the period 1871-1875 and the same from the RGO (green line). Blue and green bars depict the number of observations in each solar rotation by Secchi and RGO, respectively. Bottom panel: daily average of the number of prominences in each solar rotation for the same period.

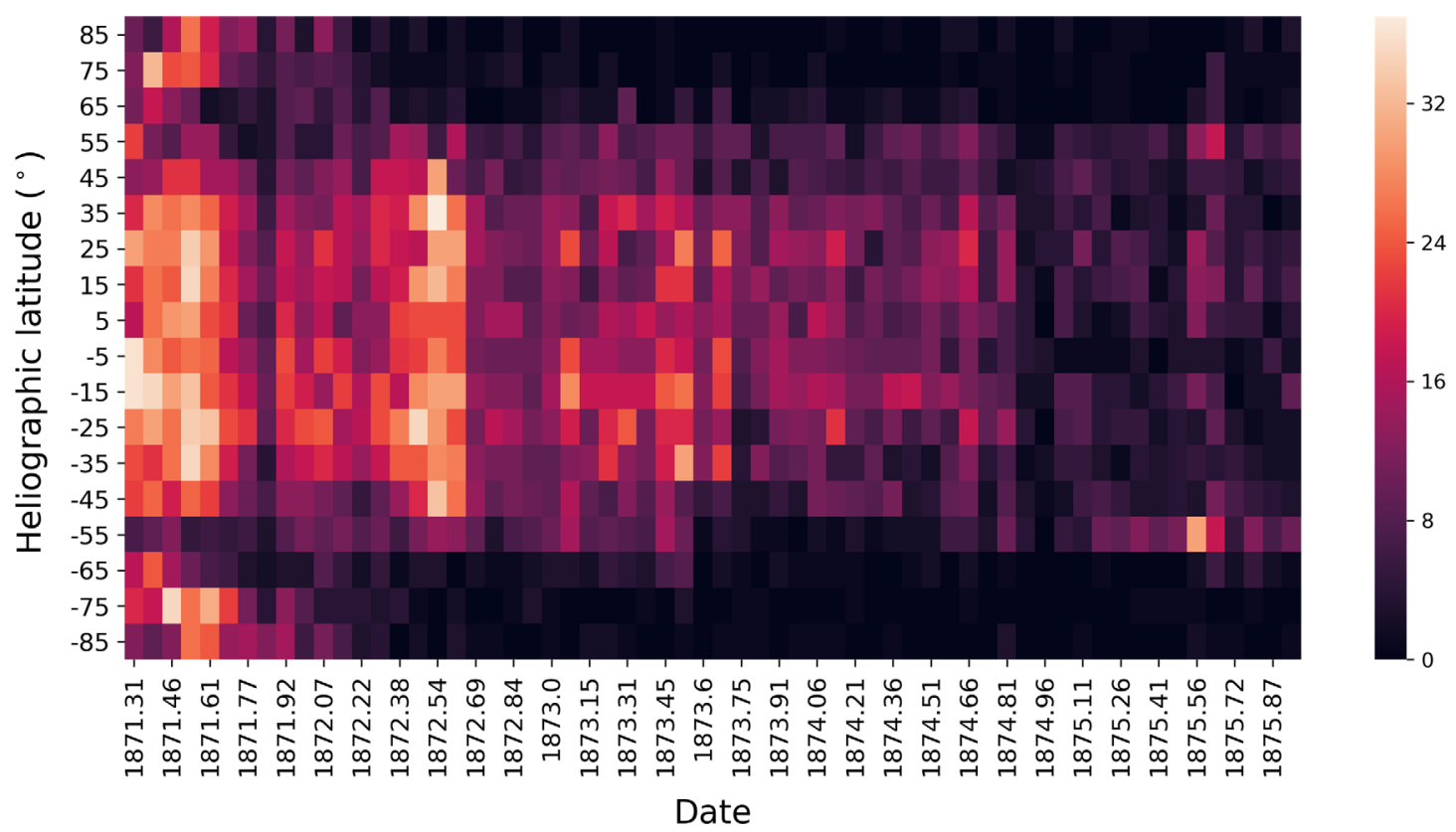

Fig. 5. Heliographic latitudes of prominences were recorded by Secchi (1875) for the period 1871-1875. Different colors represent the total number of prominences observed by latitude intervals in each solar rotation (dark colors mean less observed prominences and light colors the opposite).

Observatory (RGO) (Willis et al., 2013; Vaquero et al., 2016) corresponding to the same solar rotation defined by Secchi. In general, the number of groups recorded in RGO was lower than that by Secchi. However, this should be taken with caution because we have not considered the same observation days to calculate those values. Other reasons that can contribute to that difference can be different observation methodologies, the kind of telescope used in both observatories, and even the 
meteorological conditions. One outstanding fact is that Secchi's observations can fill gaps in the RGO series in those first two years of observations at RGO.

We also represented the daily average of the number of prominences recorded by Secchi (Fig. 4, bottom panel). It has the same behavior as that followed by sunspot groups: larger number of prominences around the maximum and values decreasing as the solar cycle progresses until the following minimum. Furthermore, we have represented the butterfly diagram of the total number of prominences recorded by Secchi (1875) in each solar rotation for 1871-1875 (Fig. 5). Dark colors depict the lowest numbers of prominences observed by Secchi whereas light colors mean the largest. The number of prominences is represented in intervals of $10^{\circ}$ in latitude as done by Secchi in his notebooks. It can be seen that the largest number of solar prominences (included at high latitudes) appear around the maximum of Solar Cycle 11. The number of prominences observed at high latitudes decreases from the maximum of the cycle to the minimum of the following solar cycle. This agrees with the result obtained by Chatterjee et al. (2020) by studying the latitude distribution of prominences from Solar Cycle 15 to 24 using data from the observatories Kodaikanal, Meudon, and Kanzelhöhe. Moreover, it can be seen that a new pattern in the number of prominences recorded by Secchi started around the end of 1875 . Note that the poleward and equatorward migration of prominences was indicated for the first time by Secchi (1872). He analyzed his solar observations made during 1871 and concluded that the number of prominences above $40^{\circ}$ and $60^{\circ}$ in latitude increased until the fourth solar rotation defined by him (around August 1871) in the case of the Northern hemisphere and the third solar rotation (around July 1871) according to the Southern hemisphere and then decreased. He also pointed out that fact coincided with the decrease of the number of spots he observed around the beginning of September 1871.

\section{Conclusions}

Angelo Secchi published in Le Soleil a summary of knowledge about our star in the early 1870s and his prominence and sunspot observations for the period 1871-1875. This book can be considered as one of the most relevant works in the history of solar physics. In fact, although prominences were observed previously, Secchi's prominence observations are the first systematic records of solar prominences available in solar physics. It is worth noting that Secchi studied the solar phenomena in collaboration with Pietro Tacchini, Lorenzo Respighi, and Giuseppe Lorenzoni. Archival documents reveal the scientific partnership existing among the above scientists.

We have digitized those observations published by Secchi, and a machine-readable version can be download on the website of HASO (http://haso.unex.es). A preliminary analysis of values included in the seven tables provided by Secchi was also made. We have identified some problems in the French and Spanish editions, which are indicated in our digitized version. Furthermore, we have compared the groups recorded by Secchi in different rotations with those made in RGO. Although the number of groups recorded by Secchi is generally larger than that in RGO, we must consider that the values were calculated based on different observation days. Therefore, it should be taken with caution. In addition, we can see that both the total number of sunspot groups in each rotation and the daily average of prominences have the same behavior: larger number around the maximum of Solar Cycle 11 and values lower as the solar cycle progresses until the minimum. Moreover, solar prominences were observed by Secchi next to solar poles around the maximum of Solar Cycle 11, whereas their number decreased from the maximum to minimum of the solar cycle. By studying his observations, Secchi could discover the migration of solar prominences toward the solar poles.

Finally, we note that all the original solar observations made by Secchi are currently being studied. More data from the important scientific activity of Angelo Secchi shall be available in the near future.

Acknowledgements. This research was supported by the Economy and Infrastructure Counselling of the Junta of Extremadura through grant GR18097 (co-financed by the European Regional Development Fund) and the Ministerio de Economía y Competitividad of the Spanish Government (CGL2017-87917-P). I.E. acknowledges funding from the Italian MIUR-PRIN grant 2017 "Circumterrestrial Environment: Impact of Sun-Earth Interaction" (grant 2017APKP7T). T.C. acknowledges funding from the German Federal Ministry of Education and Research (Project No. 01LG1909C). The authors have benefited from the participation in the workshops of the ISSI International Team 417 "Recalibration of the Sunspot Number Series" led by M.J. Owens and F. Clette.

\section{Disclosure of potential conflicts of interest}

The authors declare that they have no conflicts of interest.

\section{References}

Anonymous. 1879. Angelo Secchi. MNRAS 39: 238. https://doi.org/ 10.1093/mnras/39.4.238a.

Chatterjee S, Hegde M, Banerjee D, Ravindra B, McIntosh SW. 2020. Time-latitude distribution of prominences for 10 solar cycles: A study using Kodaikanal, Meudon, and Kanzelhohe Data, Earth and Space. Science 7: e2019EA000666. https://doi.org/ 10.1029/2019EA000666

Chinnici I. 2019. Decoding the Stars: A biography of Angelo Secchi, Jesuit and Scientist, Brill, Boston.

Chinnici I, Consolmagno G. 2021. Angelo Secchi and Nineteenth Century Science, The Multidisciplinary Contributions of a Pioneer and Innovator, Springer, Cham.

Moigno F. 1879. Le révérend père Secchi: sa vie, son observatoire, ses travaux, ses écrits à la gloire, hommages, rendus à sa mémoire, ses grands ouvrages, Gauthier-Villars, Paris.

Secchi AP. 1855. Intorno alcune nuove ricerche sullo spettro elettrico, e osservazioni sulla luce e le macchie solari. Nuovo Cimento 2: 103. https://doi.org/10.1007/BF02737941.

Secchi AP. 1864. Sulle macchie Solari. Nuovo Cimento 20: 248. https://doi.org/10.1007/BF02726913.

Secchi AP. 1871a. Osservazioni Sulle Protuberanze Solari E La Loro Distribuzione, Memorie della Società degli Spettroscopisti Italiani. Mem Soc Astron Ital 1: 33. 
Secchi AP. 1871b. Sulla Distributzione Delle Protuberanze Intorno Al Disco Solare, Memorie della Società degli Spettroscopisti Italiani. Mem Soc Astron Ital 1: 65.

Secchi AP. 1872. The solar prominences. MNRAS 32: 226. https://doi.org/10.1093/mnras/32.5.226.

Secchi AP. 1875. Le Soleil, Part 2, Gauthier-Villars, Paris.

Udías A. 2021. In Secchi own words. J Hist Astron 52: 111. https://doi.org/10.1177/0021828620979755.
Vaquero JM, Svalgaard L, Carrasco VMS, Clette F, Lefèvre L, Gallego MC, Arlt R, Aparicio AJP, Richard J-G, Howe R. 2016. A revised collection of sunspot group numbers. Sol Phys 291: 3061. https://doi.org/10.1007/s11207-016-0982-2.

Willis DM, Coffey HE, Henwood R, Erwin EH, Hoyt DV, Wild MN, Denig WF. 2013. The Greenwich photo-heliographic results (1874-1976): Summary of the observations, applications, datasets, definitions and errors. Sol Phys 288: 117. https://doi.org/10.1007/ s11207-013-0311-y.

Cite this article as: Carrasco VMS, Nogales JM, Vaquero JM, Chatzistergos T \& Ermolli I. 2021. A note on the sunspot and prominence records made by Angelo Secchi during the period 1871-1875. J. Space Weather Space Clim. 11, 51. https://doi.org/10.1051/swsc/2021033. 